This document was prepared in conjunction with work accomplished under Contract No. DE-AC09-96SR18500 with the U.S. Department of Energy.

This work was prepared under an agreement with and funded by the U.S. Government. Neither the U. S. Government or its employees, nor any of its contractors, subcontractors or their employees, makes any express or implied: 1 . warranty or assumes any legal liability for the accuracy, completeness, or for the use or results of such use of any information, product, or process disclosed; or 2 . representation that such use or results of such use would not infringe privately owned rights; or 3 . endorsement or recommendation of any specifically identified commercial product, process, or service. Any views and opinions of authors expressed in this work do not necessarily state or reflect those of the United States Government, or its contractors, or subcontractors. 


\title{
AFM characterization of laser induced damage on CdZnTe crystal surfaces
}

\section{Samantha A. Hawkins*, Lucile C. Teague, Eliel Villa-Aleman, and Martine C. Duff} Savannah River National Laboratory, Aiken, SC 29808

Arnold Burger, Michael Groza, and Vladimir Buliga

Fisk University, Nashville, TN 37208-3051

\begin{abstract}
Semi-conducting CdZnTe (or CZT) crystals can be used in a variety of detector-type applications. CZT shows great promise for use as a gamma radiation spectrometer. However, its performance is adversely affected by point defects, structural and compositional heterogeneities within the crystals, such as twinning, pipes, grain boundaries (polycrystallinity), secondary phases and in some cases, damage caused by external forces. One example is damage that occurs during characterization of the surface by a laser during Raman spectroscopy. Even minimal laser power can cause Te enriched areas on the surface to appear. The Raman spectra resulting from measurements at moderate intensity laser power show large increases in peak intensity that is attributed to Te. Atomic Force Microscopy (AFM) was used to characterize the extent of damage to the CZT crystal surface following exposure to the Raman laser. AFM data reveal localized surface damage in the areas exposed to the Raman laser beam. The degree of surface damage to the crystal is dependent on the laser power, with the most observable damage occurring at high laser power. Moreover,
\end{abstract}


intensity increases in the Te peaks of the Raman spectra are observed even at low laser power with little to no visible damage observed by AFM. AFM results also suggest that exposure to the same amount of laser power yields different amounts of surface damage depending on whether the exposed surface is the Te terminating face or the Cd terminating face of CZT.

\section{$\underline{\text { Introduction }}$}

CZT crystals have great potential for use in room-temperature gamma and X-ray spectrometers ${ }^{1-9}$. They can be grown with high purity starting materials, thus limiting the defects present in the crystal due to impurities. Additionally, methods for growing high quality CZT have improved significantly over the last decade, further advancing the quality of crystals being produced ${ }^{10-13}$. There is considerable need for reliable and reproducible methods for measuring the crystal quality so that these crystals can be put into widespread use. Characterization techniques include infrared (IR) transmission imaging, synchrotron X-ray topography, photoluminescence spectroscopy, Transmission Electron Microscopy (TEM), Atomic Force Microscopy (AFM) and Raman spectroscopy. All of these methods have been used to test for quality and/or to predict performance of the crystal as a gamma-ray detector ${ }^{1-5,8-22}$. The availability of multiple techniques will help to validate a crystal's quality and its ability to be used for either qualitative or quantitative gamma-ray or X-ray detection. 
A common defect found in CZT crystals is Te secondary phases. The Te secondary phases may be caused by different conditions, including a Te overpressure during crystal growth, uneven crystal temperatures during growth, or impurities acting as nucleation sites ${ }^{2-3,7,9,19,23}$. The secondary phases range in size and form. They can be clusters of Te atoms, symmetrical inclusions and voids with excess Te on the perimeter. The large difference between the band gap of $\mathrm{Te}, 0.33 \mathrm{eV}$, and most CZT crystals, $\sim 1.6 \mathrm{eV}$, can lead to a large loss in performance when too many secondary phases are present. This is due to changes in the detector leakage current, which result in decreased radiation spectrometer performance.

Previous experiments have shown, using Raman spectroscopy, that the localized annealing caused by tightly focused, low powered lasers result in areas of higher Te concentration on the CZT surface ${ }^{20}$. The detector performance was decreased after laser damage on the surface, likely due to the raised leakage current caused by areas of higher Te concentration. These studies were aimed at determining the mechanism of the surface damage caused by the laser.

\section{Experimental}

The CZT crystal used in this study was obtained from Yinnel Tech (South Bend, IN). It was grown by the modified vertical Bridgman (MVB) method and is made up of $\sim 10 \% \mathrm{Zn}$ content $\left(\mathrm{Cd}_{1-\mathrm{x}} \mathrm{Zn} \mathrm{n}_{\mathrm{x}} \mathrm{Te}\right.$, with $\left.\mathrm{x}=0.1\right)$. This crystal has been identified as a moderate performer for gamma-ray spectrometry. The crystal (designated CZT3-7-4) measures $12 \times 12 \times$ $3.5 \mathrm{~mm}^{3}$ and was cut along the (111) surface out of a larger boule. Both faces were finely polished with decreasing grit 
sizes of alumina; the finest was $0.05 \mu \mathrm{m}$. Prior studies have shown that polishing only, versus polishing and surface etching, produces a better performing crystal for gamma detection ${ }^{1,24}$.

The surface was exposed to an Argon ion laser (514.5 nm) in a Jobin Yvon Raman microscope system (LabRAM HR-800-UV). First, a series of six highly damaged spots were created in a line ( $20 \mathrm{~mW}$ exposure). These spots were visible under the optical microscope of both the Raman and the Atomic Force Microscopy (AFM) systems and were used as marker spots. Each spot closely matches the laser spot size of $\sim 2$ microns when viewed with an optical microscope. Next, lower laser power ( $160 \mu \mathrm{W}$ to $1.7 \mathrm{~mW})$ spots were created in a line at $\sim 10$ microns away from the marker spots, with a spacing of $\sim 10$ microns between the spots, see figure 1 . This same pattern of damage was repeated on the opposite crystal face with approximately the same laser powers in order to assess the differences between the Te terminating face and the $\mathrm{Cd}$ terminating face.

The Raman microscope used to treat the surface was also used to collect spectra of both the laser treated and untreated areas. Raman spectra were collected concurrently with the surface laser exposure using the LabRAM system with a 100X objective and a cooled charge-coupled device (CCD) camera detector. The Raman spectra of the untreated, freshly polished surface were also collected with lower laser power (less than $100 \mu \mathrm{W}$ ) in order to reduce the damage caused to the CZT crystal surface. These spectra are consistent with those reported previously ${ }^{20}$. 
The AFM images were collected using an Innova AFM system (Veeco Instruments). Images were recorded in both tapping mode and contact mode in an ambient atmosphere. AFM images were taken of laser damaged spots on both the Te terminating face and the Cd terminating face of the CZT crystal being studied.

\section{$\underline{\text { Results and Discussion }}$}

The Raman spectra of the laser damaged spots between $160 \mu \mathrm{W}$ and $1.6 \mathrm{~mW}$ on the $\mathrm{Cd}$ terminating face are shown in figure 2. The Raman spectra for the Te terminating face are virtually identical to those for the Cd terminating face. At lower laser powers Raman peaks are observed at $\sim 120,140$, and $160 \mathrm{~cm}^{-1}$. The peak at $120 \mathrm{~cm}^{-1}$ corresponds to $\mathrm{Te}^{25}$. The peaks at 140 and $160 \mathrm{~cm}^{-1}$ have previously been assigned to the transverse optic (TO) and longitudinal optic (LO) modes of CdTe respectively ${ }^{13,15-18,26}$.

During prolonged exposure to the laser, even very low power, the peak at $120 \mathrm{~cm}^{-1}$ grows from almost within the noise of the baseline to the most intense peak of the spectrum. No other new peaks appear in the spectrum. As previously shown, the peak at $140 \mathrm{~cm}^{-1}$ also becomes more intense with extended laser exposure whereas the peak at $160 \mathrm{~cm}^{-1}$ does not. This behavior has been compared to that of melted Te metal ${ }^{20}$. It is then very likely that the laser, being focused very tightly on the surface, even at low power is causing a localized annealing effect on the surface, possibly even super heating a localized region. The localized region likely has a higher Te concentration than the surrounding CZT material, as evidenced by the increase in the Te peak in the Raman spectra. Thermomigration has 
been suggested as a possible mechanism to explain the increase in Te concentration near the heated area ${ }^{27}$. It is likely that free Te atoms may be migrating to the heated areas. However, AFM suggests that Cd vaporization might also be a reason that the laser treated areas are appearing to be Te enriched.

AFM was used to probe the surface around the laser affected areas to elucidate the effect of laser annealing on the surface. Highly damaged marker spots were used to help locate the area on the crystal. An AFM topographic image and the corresponding line scan of one of the marker spots on the $\mathrm{Cd}$ terminating face is shown in figure 3 . The line scan reveals that the damaged spot resembles a crater with a depth of $\sim 0.6 \mu \mathrm{m}$ and a diameter of $\sim 1.5 \mu \mathrm{m}$, which is very similar to the diameter of the laser beam. Figure 4 shows the topographic and lateral force (friction) AFM images for the region of the $425 \mu \mathrm{W}(200 \mathrm{~s})$ and $1.7 \mathrm{~mW}(80 \mathrm{~s})$ laser treated areas on the Cd enriched face. Neither spot is visible in the topographic images; however, some contrast is observed in the friction image for the spot treated by laser at $1.7 \mathrm{~mW}$ for 80 seconds. Although the surface morphology was not greatly affected on the $\mathrm{Cd}$ terminating face, these results suggest that surface composition was sufficiently modified by the highest power and time laser exposure to be detected by AFM.

The CZT surface on the opposite face of the crystal has a higher concentration of Te atoms and is referred to as the Te terminating face. This side had a slightly greater reaction to the laser treatment. Figure 5 shows the friction image of the laser affected region of the Te terminating face of this CZT crystal, and shows both the marker spots and the varying laser power spots. The spots that were treated with the $\sim 1.7 \mathrm{~mW}$ power (both $40 \mathrm{~s}$ and $80 \mathrm{~s}$ ) were both detected in 
the AFM friction image on this face. Additionally, figure 6 shows the topographic image and corresponding line scan of the $\sim 1.7 \mathrm{~mW}(40 \mathrm{~s})$ laser treated spot on the Te terminating face. The line scan from the topographic AFM image reveals that this spot is $\sim 50 \mathrm{~nm}$ in depth and $\sim 0.5 \mu \mathrm{m}$ in diameter. Overall, AFM results indicate that the Te terminating face had more of a topographic and possible surface compositional change than the $\mathrm{Cd}$ face did with the same laser power and time exposure.

\section{Conclusion}

The Raman spectra for all of the laser treated spots show an increase in the Te peak at $120 \mathrm{~cm}^{-1}$, both with time and power. Affected spots that do not appear in the topographic AFM images are changing in composition as evidenced by the Raman spectra. However, only the spots that have been exposed to higher laser power and time can be seen in the AFM topographic images. The lateral force AFM images show some contrast in exposed areas, suggesting surface damage in the form of a possible composition change on the CZT crystal in some of the more damaged spots. The localized heating of the surface caused by the laser beam is causing craters to be formed in the surface. It appears that the Cd may be vaporizing leaving behind areas that are enriched in Te, as evidenced by the Raman spectra. These areas of Te enrichment are more metallic than the rest of the semi-conducting CZT crystal which will likely affect the leakage current on the surface. More work is needed to determine how these areas of Te enrichment will affect the detector performance of the crystal. 


\section{Acknowledgments}

Work supported by US DOE - National Nuclear Security Administration, through the Office of Nonproliferation Research and Development - NA-22 and National Science Foundation through the Fisk University Center for Physics and Chemistry of Materials (CPCoM), Cooperative Agreement CA: HRD-0420516 (CREST program) and through and from US DOE NA-22 Grant No. DE-FG52-05NA27035.

\section{$\underline{\text { References }}$}

1. M.C. Duff, D.B. Hunter, A. Burger, M. Groza, V. Buliga, and D.R. Black, Appl. Surf. Sci. (2008), in press.

2. T.E. Schlesinger, J.E. Toney, H. Yoon, E.Y. Lee, B.A. Burnett, L. Franks, and R.B. James, Mater. Sci. Eng. R 32, 103 (2001).

3. A.E. Bolotnikov, G.S. Camarda, G.A. Carini, Y. Cui, L. Li, and R.B. James, Nucl. Instrum. Methods A 579, 125 (2007). 
4. B.A. Brunett, J.M. Van Scyoc, N.R. Hilton, J.C. Lund, R.B. James, and T.E. Schlesinger, IEEE Trans. Nucl. Sci. 46, 237 (1999).

5. A. Burger, K. Chattopadhyay, H. Chen, X. Ma, J.-O. Ndap, M. Schieber, T.E. Schlesinger, H.W. Yao, J. Erickson, and R.B. James, Nucl. Instrum. Methods A 448, 586 (2000).

6. G.A. Carini, A.E. Bolotnikov, G.S. Camarda, G.W. Wright, and R.B. James, Appl. Phys. Lett. 88, 143515 (2006).

7. A.E. Bolotnikov, G.S. Camarda, G.A. Carini, Y. Cui, L. Li, and R.B. James, Nucl. Instrum. Methods A 571, 687 (2007).

8. B.A. Brunett, J.M. Van Scyoc, T.E. Schlesinger, and R.B. James, Nucl. Instrum. Methods A 458,76 (2001).

9. P.N. Luke, M. Amman, and J.S. Lee, IEEE Trans. Nucl. Sci. 51, 1199 (2004).

10. L. Li, F. Lu, K. Shah, M. Squillante, L. Cirinano, W. Tao, R.W. Olson, P. Luke, Y. Nemirovsky, A. Burger, G. Wright, and R. B. James,, IEEE Nuclear Science Symposium Conference Records, vol. 4 (2001) 2396.

11. C.M. Greaves, B.A. Brunett, J.M. Van Scyoc, T.E. Schlesinger, and R.B. James, Nucl. Instrum. Methods A 458,96 (2001).

12. M. Schieber, R.B. James, H. Hermon, A. Vilensky, I. Baydjanov, M. Goorsky, T. Lam, E. Meerson, H.W. Yao, J.

Erickson, E. Cross, A. Burger, J.O. Ndap, G. Wright, and M. Fiederle, J. Cryst. Growth 231, 235 (2001).

13. M. Sridharan, Sa.K. Narayandass, D. Mangalaraj, and H. Chul Lee, Vacuum 70, 511 (2003).

14. T. Wang, W. Jie, J. Zhang, G. Yang, D. Zeng, Y. Xu, S. Ma, H. Hua, and K. He, J. Cryst. Growth 304,313 (2007). 
15. H. Huang, J. Xu, J. Wang, C. Zhang, Y. Mo, S. Pan, G. Zhang, Procceedings of SPIE, vol4454, ed. R.E. Longshore (2001), p.244.

16. K. Prabakar, S. Venkatachalam, Y.L. Jeyachandran, Sa.K. Narayandass, and D. Mangalaraj, Mater. Sci. Eng. B-Solid 107,99 (2004).

17. M.G. Sridharan, M. Mekaladevi, Sa.K. Narayandass, D. Mangalaraj, and H. Chul Lee, J. Optoelectron. Adv. Mater. 7, 1479 (2005).

18. M.G. Sridharan, Sa.K. Narayandass, and H. Chul Lee, J. Optoelectron. Adv. Mater. 7, 1483 (2005).

19. D. Zeng, W. Jie, G. Zha, T. Wang, and G. Yang, J. Cryst. Growth 305, 50 (2007).

20. S.A. Hawkins, E.V.- Aleman, M.C. Duff, D.B. Hunter, A. Burger, M. Groza, V. Buliga, and D.R. Black, J. Electron. Mater. (2008) in press.

21. M. M.- Miranda, M. Innocenti, Appl. Surf. Sci. 226, 125 (2004).

22. A. Ruzin, I. Torchinski, and I. Goldfarb, Semicond. Sci. Technol. 19, 644 (2004).

23. T. Wang, W. Jie, and D. Zeng, Mater. Sci. Eng. A-Struct. 472, 227 (2008).

24. M.C. Duff, D.B. Hunter, P. Nuessle, D.R. Black, H. Burdette, J. Woicik, A. Burger, and M. Groza, J. Electron. Mater. 36, 1092 (2007).

25. A.S. Pine and G. Dresselhaus, Phys. Rev. B 4, 356 (1971). 
26. S. S. Islam, S. Rath, K.P. Jain, S.C. Abbi, C. Julien, and M. Balkanski, Phys. Rev. B 46, 4982 (1992).

27. H.R. Vydyanath, J. Ellsworth, J.J. Kennedy, B. Dean, C.J. Johnson, G.T. Neugebauer, J. Sepich, and P.-K. Liao, J. Vac. Sci. Technol. B 10, 1476 (1992). 


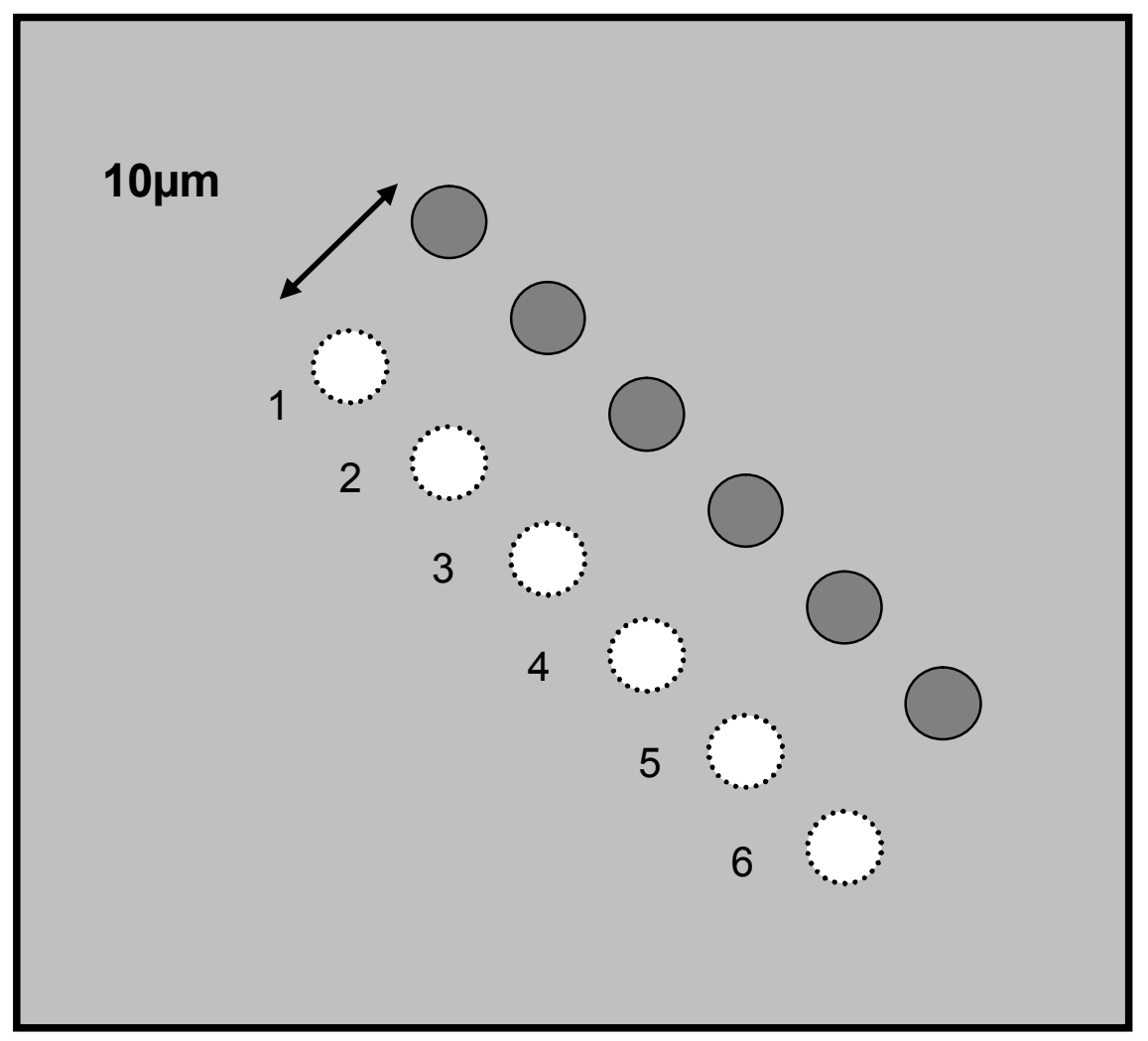

Figure 1. Scheme used for laser treatment of CZT surface by Argon ion laser. The dark "marker" spots were treated with $\sim 20 \mathrm{~mW}$ laser power with 10 second exposure time. The lighter spots were treated with the following exposure times and approximate powers: 1)1.7mW, 40s 2) $850 \mu \mathrm{W}, 40 \mathrm{~s} 3) 425 \mu \mathrm{W}, 40 \mathrm{sec}$ 4) $170 \mu \mathrm{W}, 200 \mathrm{~s} 5) 425 \mu \mathrm{W}, 200 \mathrm{~s} 6) 1.7 \mathrm{~mW}, 80 \mathrm{~s}$ 


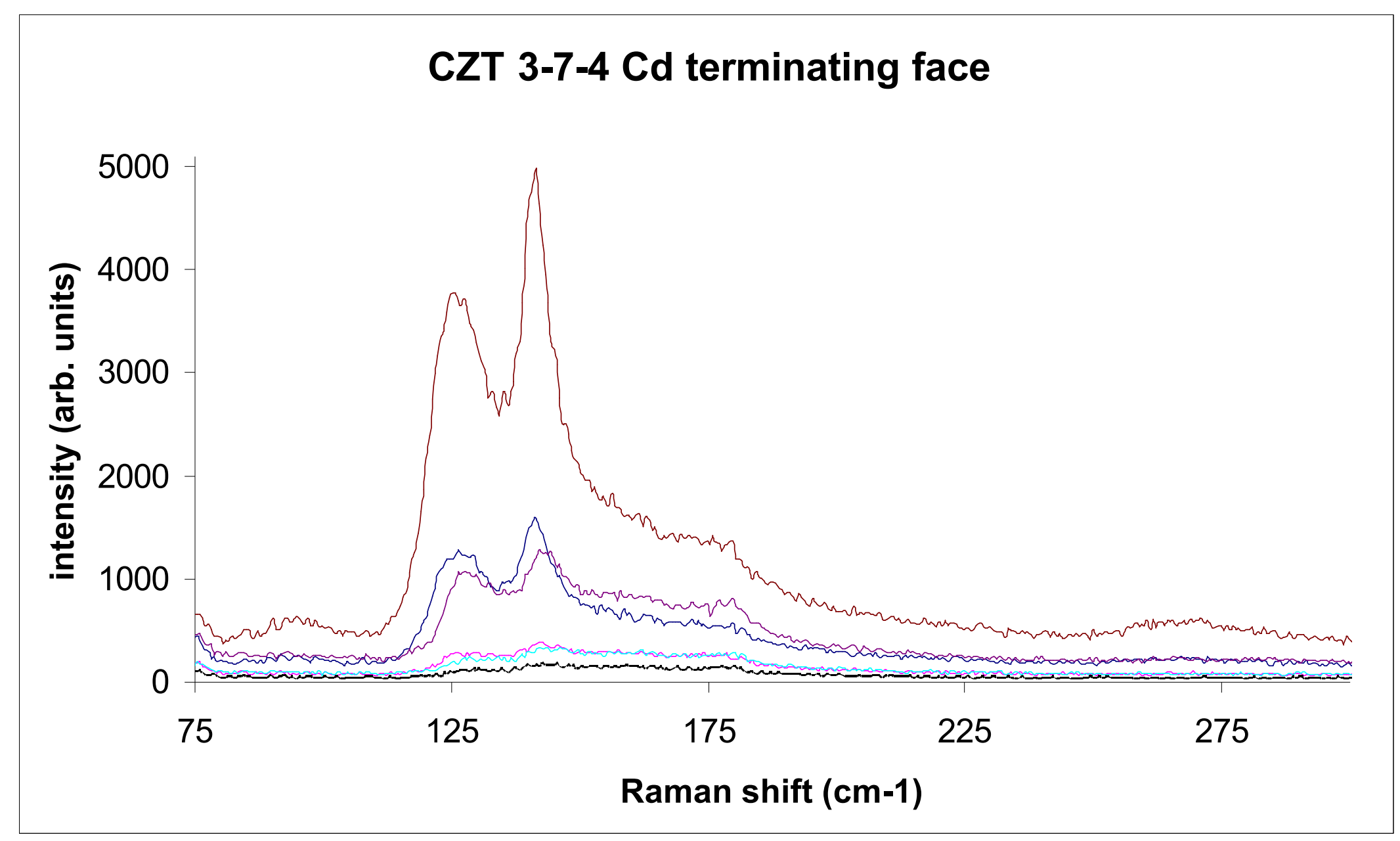

Figure 2: Raman spectra of varying laser power spots(1-6) on Cd terminating face of CZT crystal. 

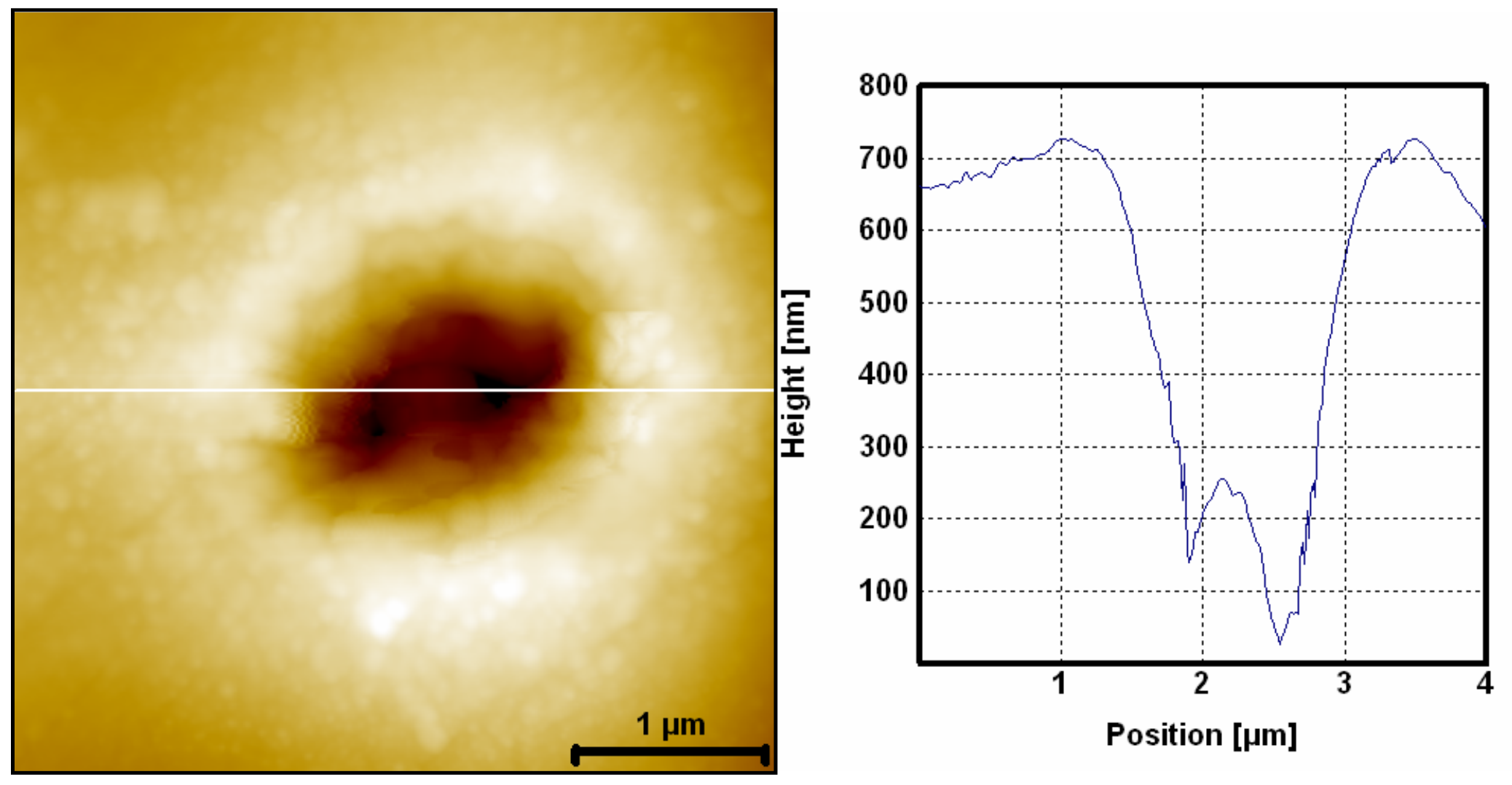

Figure 3: Topographic AFM image (contact mode) of heavily damaged spot and corresponding line scan on Cd terminating face of CZT3-7-4. 


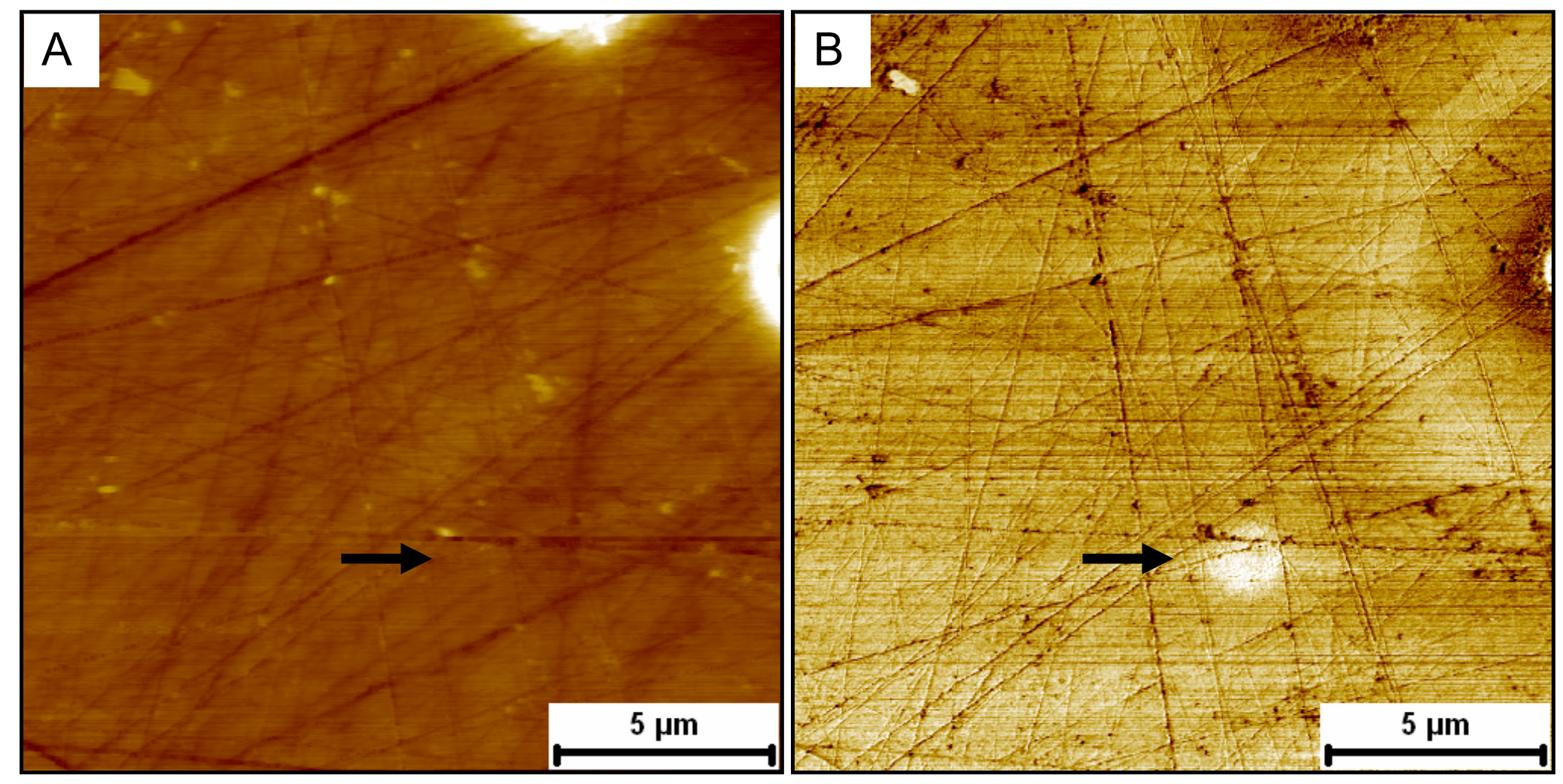

Figure 4: (A) Topographic and (B) corresponding lateral force (friction) AFM image of spots 5 and 6, Cd terminating side of CZT3-7-4. Arrow indicates damage to crystal surface observed in friction image of spot six, but no damage is observed in topography. 


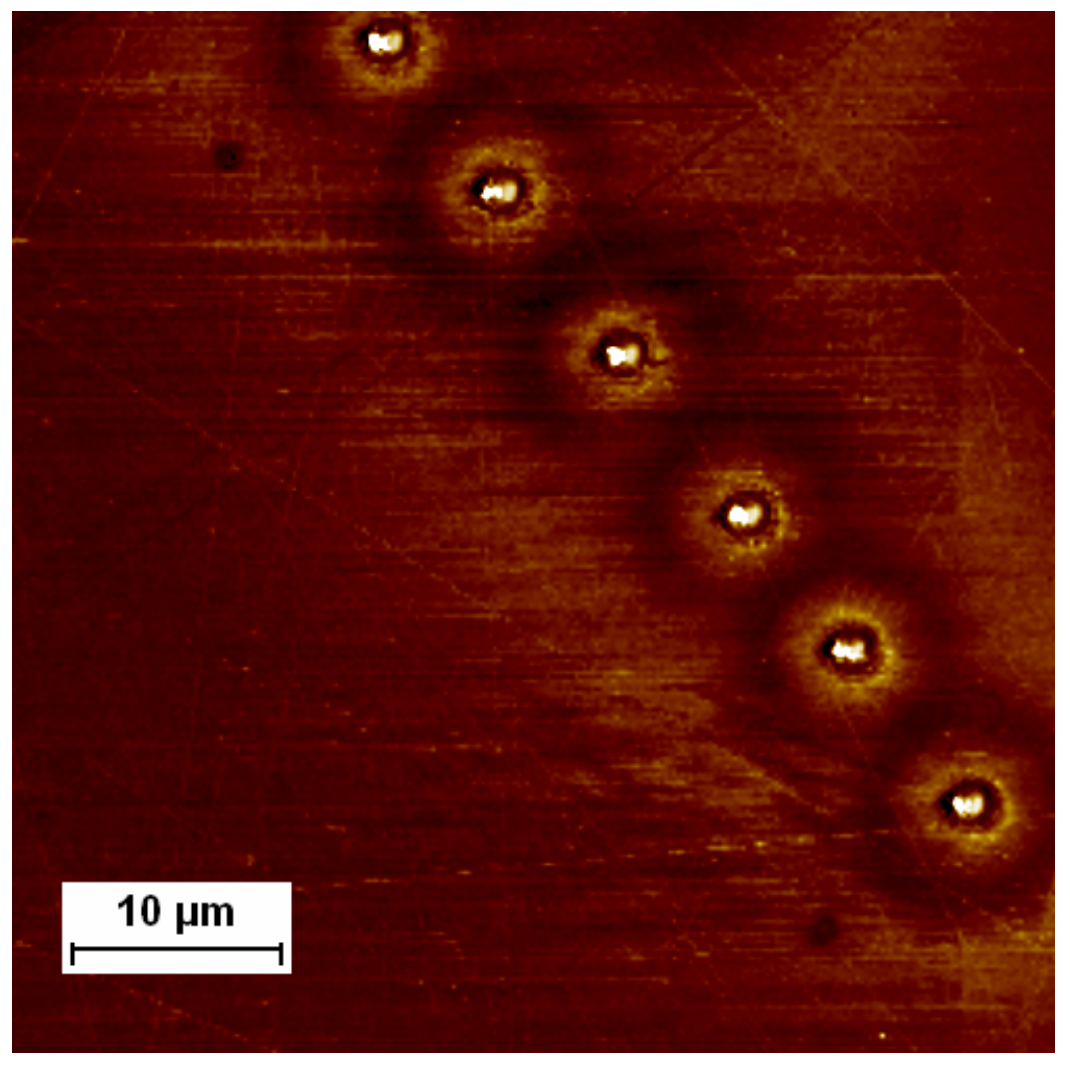

Figure 5: Lateral force (friction) AFM image of spots 1-6, side B. Friction image shows laser damage below markers for spots 1 and 6 . 

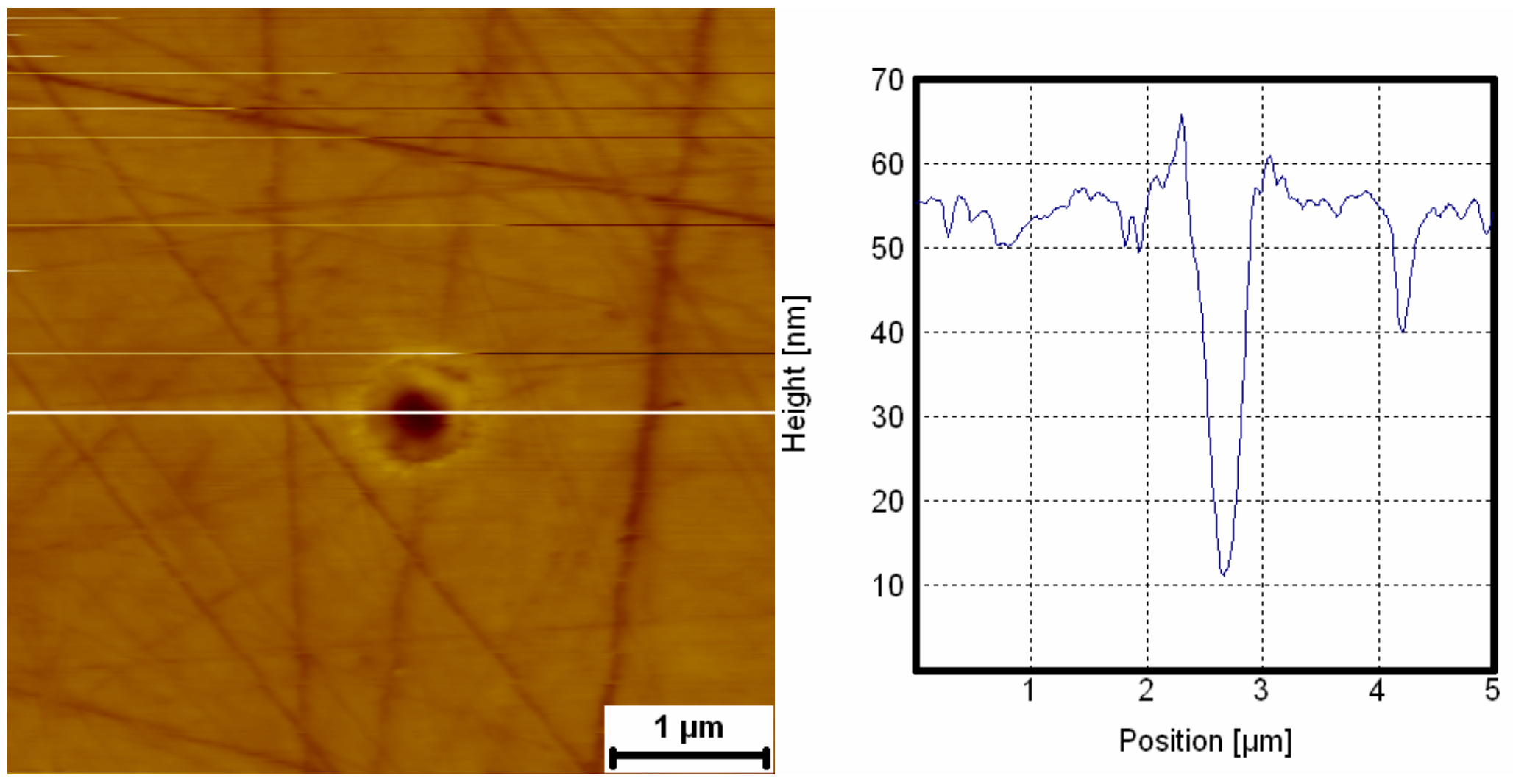

Figure 6: Topographic AFM image (contact mode) of Raman damaged spot 1 and corresponding line scan on Te terminating face of CZT3-7-4. 